\title{
O suicídio como problema de saúde coletiva na América Central Continental: uma análise dos casos consumados entre 2010-2016
}

\author{
El suicidio como problema de salud colectiva en Centroamérica \\ continental: un análisis de los casos consumados entre 2010-2016
Suicide as a collective health matter in continental Central America: an analysis of consumed cases between 2010-2016

\author{
Bel. Roberth Steven Gutiérrez Murillo ${ }^{1}$ \\ Dra. Carmen Justina Gamarra² \\ Dr. Walfrido Kühl Svoboda ${ }^{3}$ \\ Ma. Noeli Kühl Svoboda ${ }^{4}$
}

\begin{abstract}
Resumo
Na última década na América Central, como nas demais regiões latino-americanas, registrou-se notável incremento nos índices de mortalidade tendo como motivo de óbito o suicídio. Tal situação representa desafio hodierno para os sistemas de saúde e de assistência social centro-americanos. Nesse sentido, este trabalho teve por objetivo identificar o perfil dos casos de suicídios consumados entre 2010 e 2016, em países do trecho continental centro-americano. Para tanto, delineou-se um estudo ecológico, analítico-descritivo, com abordagem quantitativa, que analisou dados secundários disponibilizados pelo Observatorio Centroamericano y República Dominicana de la Conducta Suicida. Os dados foram tratados pela estatística descritiva, empregando medidas de dispersão (média, desvio padrão, limites inferior e superior), logo apresentadas por meio de tabelas comparativas, por meio de valores absolutos $(f)$ e relativos $(\%)$. Os resultados obtidos apontam que o suicídio na América Central, trecho continental, é predominantemente maior em homens $(76,84 \%)$; Guatemala foi a nação que mais registrou óbitos suicidas $(26,13 \%)$ e Belize reportou a menor incidência $(1,49 \%)$. Em relação à época do ano, houve maior número de suicídios durante o segundo trimestre dos anos verificados, ou seja, há mais mortes autoprovocadas durante os meses de abril, maio, e junho. Ressalta-se a magnitude do suicídio como problema de saúde coletiva no trecho continental da sub-região centro-americana, requisitando abordagens multidimensionais que visem entender a questão por diferentes ângulos; assim, possibilitando a proposição de intervenções interprofissionais que venham fortalecer a conscientização e a prevenção desse agravo no âmbito da saúde mental.
\end{abstract}

Palavras-Chave: Sistema de assistência social; Sistema de saúde; Suicídio; Autolesões.

\footnotetext{
1 Mestrando no Programa de Pós-graduação em Gerontologia - UNEATLÁNTICO/Espanha; Sanitarista Residente no Programa de Residência Multiprofissional em Saúde da Família - UNILA; Foz do Iguaçu, Paraná, Brasil; stevengumu@gmail.com.

2 Doutora em Saúde Coletiva - IMS/UERJ; Instituto Latino-americano de Ciências da Vida e da Natureza/ILACVN; Foz do Iguaçu, Paraná, Brasil; carmen.gamarra@unila.edu.br.

${ }^{3}$ Doutor em Ciência Animal - UEL; Instituto Latino-americano de Ciências da Vida e da Natureza/ILACVN; Foz do Iguaçu, Paraná, Brasil; walfrido.ufpr@gmail.com.
}

${ }^{4}$ Mestra em Direito - UILISBOA/Portugal; Psicóloga do Ministério Público do Paraná; Curitiba, Paraná, Brasil; noeli0310@gmail.com. 


\title{
Resumen
}

En la última década en América Central, como en otras regiones de América Latina, ha habido un aumento notable en las tasas de mortalidad con suicidio como motivo de muerte. Esta situación representa un desafío moderno para los sistemas centroamericanos de salud y asistencia social. En este sentido, este estudio tuvo como objetivo identificar el perfil de casos de suicidios consumados entre 2010 y 2016, en países de la sección continental centroamericana. Con este fin, se diseñó un estudio ecológico, analítico-descriptivo con un enfoque cuantitativo, que analizó datos secundarios proporcionados por el Observatorio Centroamericano y República Dominicana de la Conducta Suicida. Los datos se trataron mediante estadísticas descriptivas, utilizando medidas de dispersión (media, desviación estándar, límites inferior y superior), que luego se presentaron mediante tablas comparativas, mediante valores absolutos (f) y relativos (\%). Los resultados obtenidos muestran que el suicidio en América Central, un tramo continental, es predominantemente mayor en hombres (76.84\%); Guatemala fue la nación con el mayor número de muertes suicidas $(26.13 \%)$ y Belice reportó la menor incidencia (1.49\%). Con respecto a la época del año, hubo un mayor número de suicidios durante el segundo trimestre de los años verificados, es decir, hay más muertes por autolesiones durante los meses de abril, mayo y junio. Se destaca la magnitud del suicidio como un problema de salud colectivo en el tramo continental de la subregión centroamericana, que requiere enfoques multidimensionales que tengan como objetivo comprender el problema desde diferentes ángulos; permitiendo así la proposición de intervenciones interprofesionales que fortalecerán la conciencia y la prevención de este problema en el contexto de la salud mental.

Palabras claves: Sistema de asistencia social; Sistema de salud; Suicidio; Autolesiones.

\begin{abstract}
In the last decade in Central America, as in other Latin American regions, there has been a notable increase in mortality rates with suicide as the reason for death. This situation represents a modern challenge for Central American health and social care systems. In this sense, this study aimed to identify the profile of cases of suicides consummated between 2010 and 2016, in countries on the Central American continental section. To this end, an ecological, analytical-descriptive study with a quantitative approach was designed, which analyzed secondary data provided by the Observatorio Centroamericano y República Dominicana de la Conducta Suicida. The data were treated by descriptive statistics, using dispersion measures (mean, standard deviation, lower and upper limits), soon presented through comparative tables, using absolute (f) and relative (\%) values. The results obtained show that suicide in Central America, continental stretch, is predominantly greater in men (76.84\%); Guatemala was the nation with the highest number of suicidal deaths $(26.13 \%)$ and Belize reported the lowest incidence $(1.49 \%)$. Regarding the time of year, there were a higher number of suicides during the second quarter of the years verified, that is, there are more self-harm deaths during the months of April, May, and June. The magnitude of suicide is highlighted as a collective health problem in the continental stretch of the Central American sub-region, requiring multidimensional approaches that aim to understand the issue from different angles; thus, enabling the proposition of interprofessional interventions that will strengthen awareness and prevention of this problem in the context of mental health.
\end{abstract}

Keywords: Social assistance system; Health system; Suicide; Self-harm.

\section{Introdução}

O suicídio pode ser considerado como o ato planejado, coordenado e executado, no qual o indivíduo, ciente do dano e/ou prejuízo dessa ação, decide finalizar/acabar voluntariamente com sua própria vida (ORGANIZAÇÃO PAN-AMERICANA DA SAÚDE OPAS, 2018). Segundo Mora; Moya; Calderón (2019), o termo "suicídio" vem do latim, da união das palavras "sui", que significa "de si mesmo" e “caedere" "matar-se". Venco e Barreto (2014, p. 3), por sua vez, comentam que "o suicídio se inscreve no campo dos transtornos mentais, adquirindo o status de patologia". Seguem que, na atualidade, "o suicídio continua sendo sustentado por crenças e mitos que se alimentam do corpo biológico para 
explicar o que nos angustia”. Fernández et al. (2012) definem suicídio como a mais extrema manifestação de violência que um indivíduo pode realizar contra si mesmo.

De acordo com a OPAS (2018) o suicídio é um grave problema de saúde coletiva/pública, sendo necessária para sua prevenção uma resposta nacional estratégica e multissetorial. A ocorrência do suicídio apresentava predominância nos países de baixa e de média renda per capita, sendo a segunda principal causa de morte entre jovens de 15 a 29 anos, no mundo, em 2016. Ampliando o panorama epidemiológico, o suicídio configura um importante desafio para a saúde pública por ser um comportamento que desobedece às leis biológicas e que ofende crenças religiosas fortemente enraizadas nas sociedades, cercando sua abordagem/intervenção de tabus ideológicos assistenciais.

Em outra perspectiva, a Classificação Internacional de Doenças (CID), em sua $11^{\mathrm{a}}$ versão, elaborada pela Organización Mundial de la Salud (OMS), enquadra o suicídio dentro das causas externas de morbidade e de mortalidade, na categoria "lesões autoprovocadas voluntariamente", tendo como possíveis motivos de óbito: evento de transporte; queda; contato com pessoa, animal ou planta; contato com objeto não classificado em outra parte; imersão, submersão ou queda na água; comprometimento respiratório; mecanismo térmico; exposição a substâncias ou seus efeitos nocivos; exposição a outros mecanismos (OMS, 2019).

Relatórios oficiais apresentados por Organizações Internacionais, que têm como ponto principal de estudo e de intervenção a saúde humana nas esferas individual e coletiva, vêm relevando importância à compreensão multidimensional/multifatorial do suicídio. Tal fato ocorre tanto no intuito de identificar possíveis comportamentos individuais e/ou coletivos, que permitam abordar o indivíduo em tentativa de suicídio para, intervir e coibir a consumação do ato suicida; quanto para analisar as características sociodemográficas que permitam traçar um perfil epidemiológico, a fim de subsidiar o posicionamento estatal no combate e na conscientização sobre o suicídio como problema de saúde coletiva/pública, por meio da elaboração de políticas públicas intersetoriais e de programas específicos para esse fim.

Conforme o "Informe Regional: Mortalidad por suicidio en las Américas", publicado pela OPAS em 2014, a sub-região centro-americana alcançou entre 2005-2009, uma taxa geral ajustada de 5,3 casos por cada 100.000 habitantes, correspondendo a 8,50 casos em homens e 2,02 em mulheres. Em comparação, o Continente Americano (em todas as subregiões), registrou uma taxa geral ajustada de 7,26 casos por cada 100.000 habitantes, sendo 11,54 para homens e 3,04 para mulheres (OPAS, 2014). Esse relatório também enfatiza que "o suicídio constitui um problema de saúde pública de extrema importância nas Américas" 
(tradução livre do espanhol), uma vez que o suicídio representou, nesse período, 12,4\% das causas externas de óbito (OPAS, 2014, p. 05).

A América Central Continental (ACC), sub-região com menor densidade populacional e extensão territorial do Continente Americano, é conformada por sete nações, a saber: Belize, Costa Rica, El Salvador, Guatemala, Honduras, Nicarágua, e Panamá. Sua localização geográfica a converte em uma ponte entre as regiões sul e norte do continente. A língua espanhola é predominante no território, sendo que Belize é o único país que tem o inglês como língua oficial.

Na última década na América Central, como nos demais países latino-americanos, registrou-se notável incremento nos índices de mortalidade tendo como motivo de óbito o suicídio. Tal situação espelha desafio hodierno para os sistemas de saúde e de assistência social, na medida em que requer capacidade de abordagem teórica-técnica-prática que considere as características e o perfil multidimensional dos óbitos registrados. Requisita, inclusive, qualificação e aperfeiçoamento dos profissionais que se encontram em contato direto com indivíduos com histórico de tentativa e/ou em possível condição de vulnerabilidade que propicie a consumação do ato suicida.

A realidade sociossanitária da ACC é abordada de forma coletiva por todos os países membros através do Consejo de Ministros de Salud de Centroaméricana (COMISCA), que, por sua vez, é um órgão oficial do Sistema de Integración Centroamericano (SICA). Assim, o COMISCA tem por propósito principal identificar e priorizar os problemas sub-regionais de saúde nos territórios continentais centro-americanos (SICA, 2013). Nesse contexto de responsabilização sub-regional, o COMISCA tem adotado uma série de medidas que buscam facilitar mecanismos e recursos para todos os países, na busca pelo cuidado integral às premências sociossanitárias da sub-região. Exemplo disso é a criação do Observatorio Centroamericano y República Dominicana de la Conduta Suicida, uma ferramenta estatística para a coleta de informações epidemiológicas que permitam caracterizar os riscos populacionais em geral e, contribuir efetivamente para conhecer o comportamento da conduta suicida na sub-região; enfatizando os riscos, justamente, para embasar de modo mais adequado a proposição de medidas preventivas em saúde mental e social (COMISCA, 2018). Sendo assim, os países centro-americanos são instilados a submeter relatórios trimestrais sobre os registros de mortalidade, tendo como fundamento o obituário de suicídios.

Entendendo a magnitude do suicídio como problema de saúde mundial e o direcionamento do estudo às realidades sociossanitárias da sub-região centro-americana, especialmente, no que tange à saúde mental coletiva; delineou-se como objetivo geral de 
pesquisa traçar o perfil dos casos consumados por suicídio em países continentais centroamericanos, entre os anos de 2010 a 2016.

\subsection{Perfil sociossanitário da ACC: qual é a realidade sub-regional?}

De acordo com Schneider (2014, p. 01), “o perfil sociossanitário de um determinado país é caracterizado pelo conjunto de condições econômicas, sanitárias e sociais em que as pessoas nascem, vivem, trabalham e envelhecem". Comenta ainda que "a abordagem dessas condições deve reconhecer o fato de que as iniquidades em saúde não podem ser combatidas sem que as iniquidades sociais também o sejam".

Com o intuito de conhecer o perfil sociossanitário dos países da ACC, realizou-se consulta à base virtual de dados e estatísticas da Comisión Económica para América Latina y el Caribe (CEPALSTAT), obtendo os números apresentados pelos países nos âmbitos econômico, social e sanitário. A Tabela 01, abaixo, apresenta a relação das características sociossanitária da sub-região continental centro-americana, segundo variável, país e ano.

Tabela 01 - Perfil sociossanitário da América Central Continental segundo projeções da CEPALSTAT

\begin{tabular}{|c|c|c|c|c|c|c|c|c|}
\hline País & População* & TBN* & TBM* & TM* & EVGanos* & PIEPIBEdu*** & PIEPIBSau** & PIEPIBSoc ${ }^{* * * * *}$ \\
\hline Belize & 398,000 & 19.6 & 4.9 & 2.6 & 75 & $7.4 \%$ & $6.2 \%$ & - \\
\hline Costa Rica & $5.094,000$ & 12.7 & 5.4 & 0.7 & 81 & $7.4 \%$ & $8.1 \%$ & $24.0 \%$ \\
\hline $\begin{array}{l}\text { El } \\
\text { Salvador }\end{array}$ & $6.486,000$ & 17.2 & 7.2 & -5.2 & 74 & $3.8 \%$ & $6.9 \%$ & $14.6 \%$ \\
\hline Guatemala & $17.916,000$ & 23.0 & 4.7 & -0.5 & 75 & $2.8 \%$ & $5.7 \%$ & $7.0 \%$ \\
\hline Honduras & $9.905,000$ & 20.3 & 4.5 & -0.5 & 76 & $6.0 \%$ & $7.6 \%$ & $8.0 \%$ \\
\hline Nicarágua & $6.625,000$ & 18.7 & 5.1 & -2.4 & 75 & $4.3 \%$ & $7.8 \%$ & $11.1 \%$ \\
\hline Panamá & $4.315,000$ & 17.9 & 5.3 & 1.7 & 79 & $3.2 \%$ & $7.0 \%$ & $8.8 \%$ \\
\hline MR $_{\text {CAC }}$ & $7.248,429$ & 18.4 & 5.3 & -3.6 & 76 & $5.0 \%$ & $7.0 \%$ & $12.25 \%$ \\
\hline \multicolumn{9}{|c|}{$\begin{array}{l}\text { MR }_{\text {CAC: }} \text { Média sub-regional centro-americana continental; TBN: Taxa bruta de natalidade; TBM: Taxa bruta de } \\
\text { mortalidade; TM: Taxa de migração; EVG: Esperança de vida geral (expressa em anos absolutos); PIEPIBEdu: } \\
\text { Proporção de investimento estatal sob o produto interno bruto em educação; PIEPIBSau: Proporção de } \\
\text { investimento estatal sob o produto interno bruto em saúde; PIEPIBSoc: Proporção de investimento estatal sob o } \\
\text { produto interno bruto em social. *Projeções 2020/2025; **Projeções 2015; ***Projeções 2017; ****Projeções } \\
2018 \text {. }\end{array}$} \\
\hline
\end{tabular}

Fonte: Elaboração própria dos autores (2020).

Com base nos dados supramencionados, é possível afirmar que a Guatemala é a nação continental centro-americana mais populosa, abrangendo 35,3\% da população total da ACC. 
Costa Rica, El Salvador, e Panamá são os três países com menor TBN, em relação à MR $\mathrm{MAC}_{\text {, }}$ respetivamente $(12.2,17.2,17.9 ; 18.4)$. A TBM média da ACC é de 5.3 óbitos por cada 100.000hab, sendo que El Salvador apresenta 1.9 mortes acima da MR $_{\mathrm{CAC}}$ e Honduras, Guatemala, e Belize valores inferiores à média. No que concerne à TM, observa-se notória divergência entre os países, colocando à Costa Rica como o país com menor número de migrantes $(0.7 ;-3.6)$ e evidenciando uma tendência de migração bastante elevada em El Salvador, Nicarágua e Honduras (-5.2, -2.4, -0.5; -3.6).

A EVG média centro-americana é de 76 anos, sendo que os cidadãos costa-riquenhos e panamenhos podem esperar viver mais $\left(81 ; 79\right.$ anos). Em relação à $\mathrm{MR}_{\mathrm{CAC}}$ da PIEPIB $\mathrm{Edu}$ constata-se $5.0 \%$, ao que é visível que a maioria dos países não consegue atingir tal valor, merecendo destaque do Estado costa-riquenho e belizenho, ao investirem $+2.4 \%$. Ademais, é acenar para uma MR $\mathrm{MAC}_{\mathrm{C}}$ sobre a PIEPIB Sau $_{\text {de }} 7.0 \%$, da qual Guatemala e Belize apresentam maiores desafios para a atingirem. Finalmente, observa-se uma $\mathrm{MR}_{\mathrm{CAC}}$ da PIEPIB ${ }_{\text {Soc }}$ igual a 12.25\%, destacando-se à Costa Rica e El Salvador, por serem as únicas nações com gasto público social acima da média, inclusive, a Costa Rica investindo 50\% mais do que os demais países da sub-região.

Em uma visão geral, projeta-se que as realidades sociossanitárias da Costa Rica e do Panamá sejam mais favoráveis para o desenvolvimento humano (segundo seus índices econômicos, sociais e sanitários), quando comparadas aos demais países centro-americanos. Em divergência, observa-se maior obstáculo para o desenvolvimento em El Salvador, Guatemala, e Honduras, requerendo trabalho intersetorial do setor público, com reforço do setor privado, para a obtenção de melhores resultados; que seriam traduzidos em melhor qualidade e em melhores condições de vida para seus cidadãos. A partir dos dados analisados, questiona-se: a incidência dos suicídios consumados nos países continentais centroamericanos estaria relacionada ao perfil sociossanitário dos mesmos; isso é, países com piores condições sociossanitárias apresentariam maior número de suicídios consumados?

\section{Metodologia}

O embasamento teórico-metodológico da pesquisa enquadra-se no tipo ecológico misto (de séries temporais e de múltiplos grupos), de cunho analítico-descritivo, com viés quantitativo. Os estudos ecológicos são similares aos estudos transversais, com a diferença básica de que não medem desfechos em indivíduos, e sim em populações (ARAGÃO, 2011). Ademais, Lima-Costa e Barreto (2003) abordam importante descrição, em relação aos estudos do tipo ecológico, esclarecendo que: 


\begin{abstract}
Nos estudos ecológicos, compara-se a ocorrência da doença/condição relacionada à saúde e a exposição de interesse entre agregados de indivíduos (populações de países, regiões ou municípios, por exemplo) para verificar a possível existência de associação entre elas. Em um estudo ecológico típico, medidas de agregados da exposição e da doença são comparadas. Nesse tipo de estudo, não existem informações sobre a doença e exposição do indivíduo, mas do grupo populacional como um todo. Uma das suas vantagens é a possibilidade de examinar associações entre exposição e doença/condição relacionada na coletividade. Isso é particularmente importante quando se considera que a expressão coletiva de um fenômeno pode diferir da soma das partes do mesmo fenômeno. Por outro lado, embora uma associação ecológica possa refletir, corretamente, uma associação causal entre a exposição e a doença/ condição relacionada à saúde, a possibilidade do viés ecológico é sempre lembrada como uma limitação para o uso de correlações ecológicas. O viés ecológico - ou falácia ecológica - é possível porque uma associação observada entre agregados não significa, obrigatoriamente, que a mesma associação ocorra em nível de indivíduos (LIMA-COSTA; BARRETO, 2003, p. 194).
\end{abstract}

No presente trabalho, todos os países que conformam à sub-região continental centroamericana foram tomados como unidades de estudo. Como variáveis dependentes contabilizaram-se os casos de suicídio consumados, e como variáveis independentes, o sexo e a nacionalidade do agente, juntamente, com o trimestre e o ano de registro obituário. No tangente à tipificação dos dados, consideraram-se dados de origem secundária, que se encontram liberados e disponíveis para consulta pública pela internet.

\title{
2.1. Instrumento e coleta de dados
}

A extração dos dados foi realizada ao longo do mês de dezembro de 2019. Previamente, elaborou-se um roteiro estruturado contendo dados relativos ao perfil do caso consumado de suicídio (variáveis dependentes e independentes), em um banco de dados no Software Microsoft Excel®, de livre licença para iOS, servindo como ferramenta para a tabulação e a agrupação dos dados. Os dados foram recuperados do sítio on-line do Observatorio Centroamericano y República Dominicana de la Conducta Suicida. O site, por sua vez, possui registro de óbitos por suicídio de 2010 a 2018.

Os dados foram obtidos respeitando as seguintes variáveis de interesse: ano (2010, 2011, 2012, 2013, 2014, 2015, e 2016); trimestre (1, 2, 3, e 4); sexo (masculino e feminino); país (Belize, Costa Rica, El Salvador, Guatemala, Honduras, Nicarágua e Panamá).

Faz-se importante mencionar que a escolha pelo período de 2010 a 2016 deveu-se ao fato de alguns países não apresentarem registros para os anos de 2017 e 2018, o que impossibilitou realizar uma análise integral de todos os anos disponíveis no sítio on-line.

\subsection{Critérios de inclusão e de exclusão}


Foram incluídos todos os registros anuais dos casos de suicídio consumado, publicados na base de dados do Observatorio Centroamericano y República Dominicana de la Conducta Suicida, que tiveram como local de óbito qualquer país continental centroamericano. Excluíram-se dados referentes à República Dominicana, pois esse país não faz parte dos estados centro-americanos por questões geopolíticas, principalmente, pela sua localização geográfica no Caribe hispano. Ademais, considerando os objetivos deste estudo, somente foram contemplados os países da sub-região continental, por isso os países insulares centro-americanos foram excluidos do estudo.

\subsection{Análise dos dados e abordagem estatística}

Os dados processados foram analisados por meio da abordagem quantitativa, empregando à técnica da estatística descritiva, com utilização de medidas de dispersão (média; desvio padrão; limite inferior, e limite superior). "A estatística descritiva se preocupa em oferecer descrições, por meio da coleta, apresentação e interpretação adequada de um conjunto de dados numéricos ou não" (GUEDES et al., 2005, p. 01).

Tendo em mente que o Observatorio Centroamericano y República Dominicana de la Conducta Suicida agrupa os dados segundo o trimestre do ano em que ocorreu a morte, somaram-se todos os registros trimestrais, com vistas a totalizar o perfil anual das causas consumadas de suicídio, para cada país, logo filtrados segundo o sexo do agente. As informações foram apresentadas por meio de tabelas comparativas, com valores absolutos $(f)$, e relativos $(\%)$.

O estudo respeitou as orientações bioéticas de pesquisa em saúde, em concordância com a Resolução nº 446, do Ministério da Saúde do Brasil - MS, não havendo sido necessária a aprovação do Comitê de Ética em Pesquisa (MS, 2012).

\section{Resultados}

A Tabela 02, abaixo, expressa a relação dos suicídios consumados, segundo país e período observado (anos de 2010 a 2016). Identificou-se um total de 9744 casos de suicídios consumados na ACC, sendo: $\bar{X}=1392, S=431.86$ óbitos anuais por suicídio; 2013 foi o ano com maior taxa de incidência $(18,14 \%)$, e 2016, o ano no qual houve menor registro de mortalidade $(4,69 \%)$.

A Guatemala, embora não tenha apresentado dados em 2016, posicionou-se como o país com a média mais elevada de suicídios consumados $(\bar{X}$ anual=366; $S=146.56)$, obtendo o limite superior mais alto da sub-região continental centro-americana (481 suicídios 
consumados em 2014, sendo responsável por 27,9\% do registro de mortes autoprovocadas nesse mesmo ano). Em contrapartida, o número de suicídios consumados em Belize foi o mais baixo da sub-região. Nesse território, conheceram-se apenas $\bar{X}=21 ; S=6.07$ casos anuais e, consequentemente, o referido país também obteve o limite inferior mais baixo (17 casos entre 2012 e 2013), representando apenas 1,05\% do total dos casos registrados nesses anos.

Faz-se importante notar, ainda, que o comportamento suicida foi fatal em países como Nicarágua, Costa Rica e El Salvador, uma vez que as médias anuais dos mesmos representam importante peso no cálculo do índice de mortalidade sub-regional por suicídio consumado. Ao se somarem os valores totais, observou-se que 55,8\% (ou 5437) dos óbitos totais, se concentraram nesses três países.

Tabela 02 - Total de suicídios consumados na América Central Continental, segundo país, entre 2010 e 2016

\begin{tabular}{|c|c|c|c|c|c|c|c|c|c|c|c|c|c|c|c|c|}
\hline \multirow{3}{*}{$\stackrel{\Omega}{\Omega}$} & \multicolumn{16}{|c|}{$\mathrm{N}=9744$} \\
\hline & \multicolumn{2}{|c|}{2010} & \multicolumn{2}{|c|}{2011} & \multicolumn{2}{|c|}{2012} & \multicolumn{2}{|c|}{2013} & \multicolumn{2}{|c|}{2014} & \multicolumn{2}{|c|}{2015} & \multicolumn{2}{|c|}{2016} & \multirow[b]{2}{*}{ 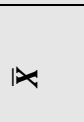 } & \multirow[b]{2}{*}{$\infty$} \\
\hline & $f$ & $\%$ & $f$ & $\%$ & $f$ & $\%$ & $f$ & $\%$ & $f$ & $\%$ & $f$ & $\%$ & $f$ & $\%$ & & \\
\hline$B L Z$ & 16 & 1,08 & 35 & 2,3 & 17 & 1,2 & 17 & 0,9 & 24 & 1,3 & 19 & 1,4 & 17 & 3,7 & 21 & 6.07 \\
\hline$C R C$ & 296 & 20,0 & 318 & 21,1 & 210 & 14,4 & 312 & 17,5 & 270 & 15,7 & 296 & 22,8 & 137 & 29,9 & 263 & 61.34 \\
\hline$S L V$ & 210 & 14,2 & 253 & 16,8 & 262 & 18,0 & 237 & 13,3 & 262 & 15,2 & 174 & 13,4 & 140 & 30,6 & 220 & 47.44 \\
\hline GTM & 405 & 26,3 & 339 & 22,5 & 435 & 29,9 & 478 & 26,9 & 481 & 27,9 & 56 & 4,3 & $*$ & $*$ & 366 & 146.56 \\
\hline$H N D$ & 63 & 4,2 & 49 & 3,2 & 79 & 5,4 & 244 & 13,7 & 235 & 13,6 & 327 & 25,2 & 72 & 15,7 & 153 & 104.36 \\
\hline$N G R$ & 398 & 27,0 & 369 & 24,5 & 316 & 21,7 & 351 & 19,7 & 311 & 18,0 & 315 & 24,2 & $*$ & $*$ & 343 & 32.41 \\
\hline$P N M$ & 151 & 10,2 & 144 & 9,5 & 135 & 9,2 & 129 & 7,26 & 139 & 8,0 & 110 & 8,5 & 91 & 21,0 & 128 & 54.49 \\
\hline
\end{tabular}

BLZ: Belize; CRC: Costa Rica; SLV: El Salvador; GTM: Guatemala; HND: Honduras; NGR: Nicarágua; PNM: Panamá; S: Desvio padrão; $\bar{X}$ : Média aritmética. *Dados não disponíveis.

Fonte: Elaboração própria dos autores (2020).

A Figura 01, abaixo, mostra a dispersão entre sexo, segundo total dos suicídios consumados e país de origem dos agentes. Após análise estatística, identificou-se predominância $(76,84 \%)$ do ato suicida em homens. Tal fenômeno epidemiológico foi percebido em todos os países da ACC, destacando-se como um problema de saúde coletiva que deve ser compreendido através da perspectiva relativa às diferenças sociais/culturais entre os sexos. Nesse sentido, ao interpretar as informações sob um recorte de sexo, fazem-se as seguintes asseverações: 
1. Centro-americanos continentais do sexo masculino apresentam maior probabilidade de consumar suicídio, totalizando, em média $\bar{X}=1070 ; S=551.84$ mortes anuais na subregião;

2. Homens de nacionalidades guatemalteca, costa-riquenha, ou nicaraguense acumulam mais da metade do total das mortes masculinas na sub-região (4740 ou 63,3\%);

3. Embora mulheres pratiquem menor número de suicídio, evidenciam-se dados alarmantes entre as hondurenhas e as nicaraguenses, estando, respectivamente, $19,12 \%$ e 16,67\% acima da média de suicídios femininos na ACC;

4. O computo absoluto dos suicídios projeta que esse é um fenômeno predominante no sexo masculino, e que a distribuição dos óbitos femininos parece convergir com o padrão lateralizado em homens (ver limites focais, Figura 01).

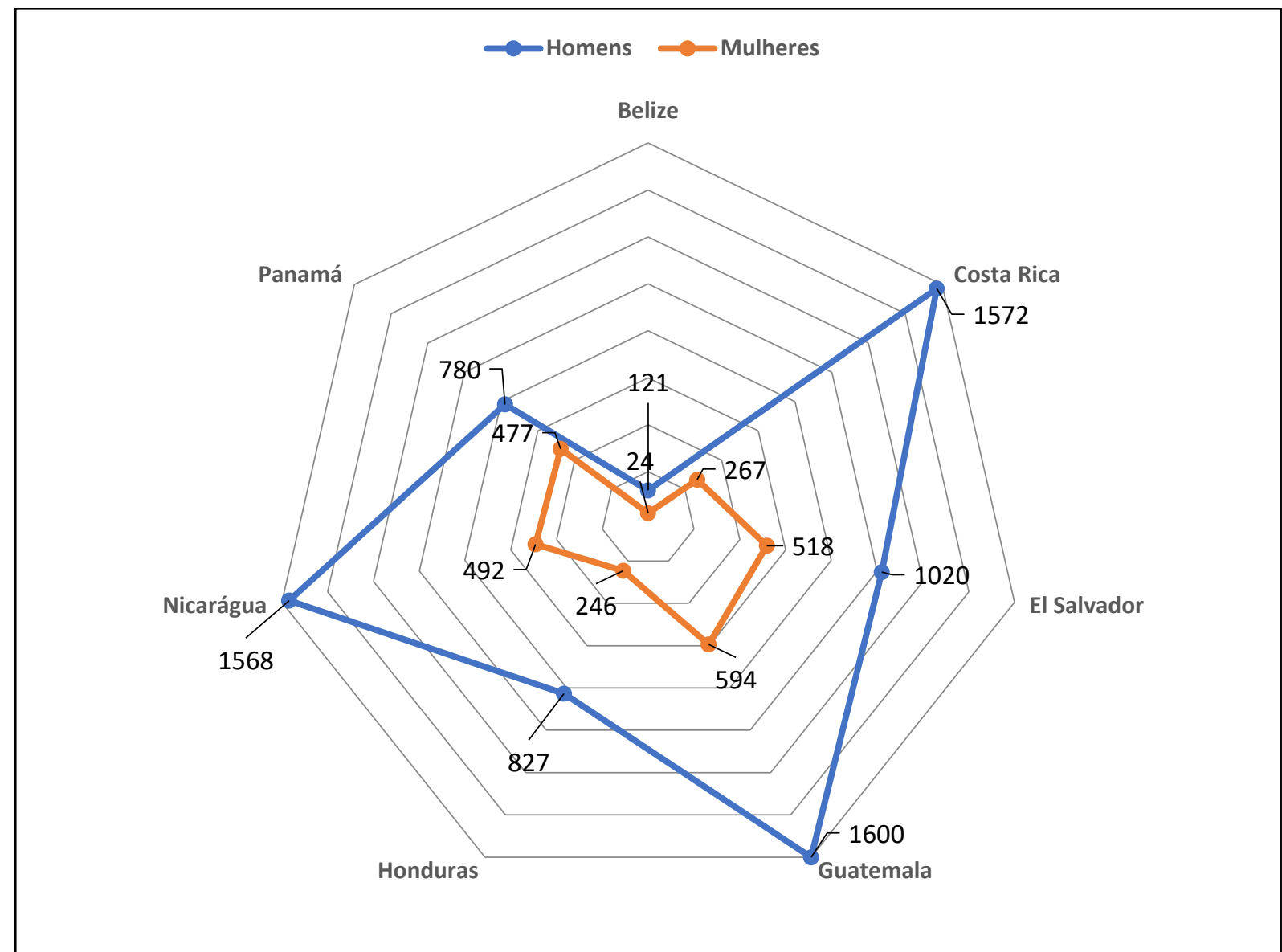

Figura 01 - Distribuição dos casos consumados de suicídio segundo sexo e país de origem dos agentes, América Central Continental, 2010-2016.

Fonte: Elaboração própria dos autores (2020).

A despeito da tendência de mortalidade costumar ser estudada por meio de valores anuais absolutos, também pode ser analisada através da interpretação dos registros de óbitos trimestrais. Nesse sentido, a Figura 02, abaixo, permite observar a relação das mortes 
registradas, segundo o trimestre do ano e o país de origem dos agentes que praticaram condutas suicidas. Informações desse estudo apontam que, de forma geral, o segundo trimestre apresentou maior número de suicídios consumados $(\mathrm{n}=2583 ; 26,5 \%)$, seguido pelo terceiro trimestre, $(\mathrm{n}=2523 ; 25,89 \%)$. O primeiro trimestre mostrou declínio da mortalidade, pois nessa época do ano foram totalizados 2447 suicídios $(25,11 \%)$. Por fim, no quarto trimestre, identificou-se menor grau de consumação suicida $(n=2191 ; 22,48 \%)$.

Das informações anteriores retém-se que, durante os meses de abril, maio, e junho, é possível esperar maior número de mortes suicidas na sub-região continental centro-americana. Nos últimos três meses do ano, no entanto, a fatalidade tende a diminuir. Datas como Natal e virada do ano poderiam ser fatores protetores no quarto trimestre; contudo, considera-se necessário aprofundar as pesquisas qualitativas que visem entender os perfis dos agentes que realizam tentativa suicida, buscando possíveis relações espaço-temporais.

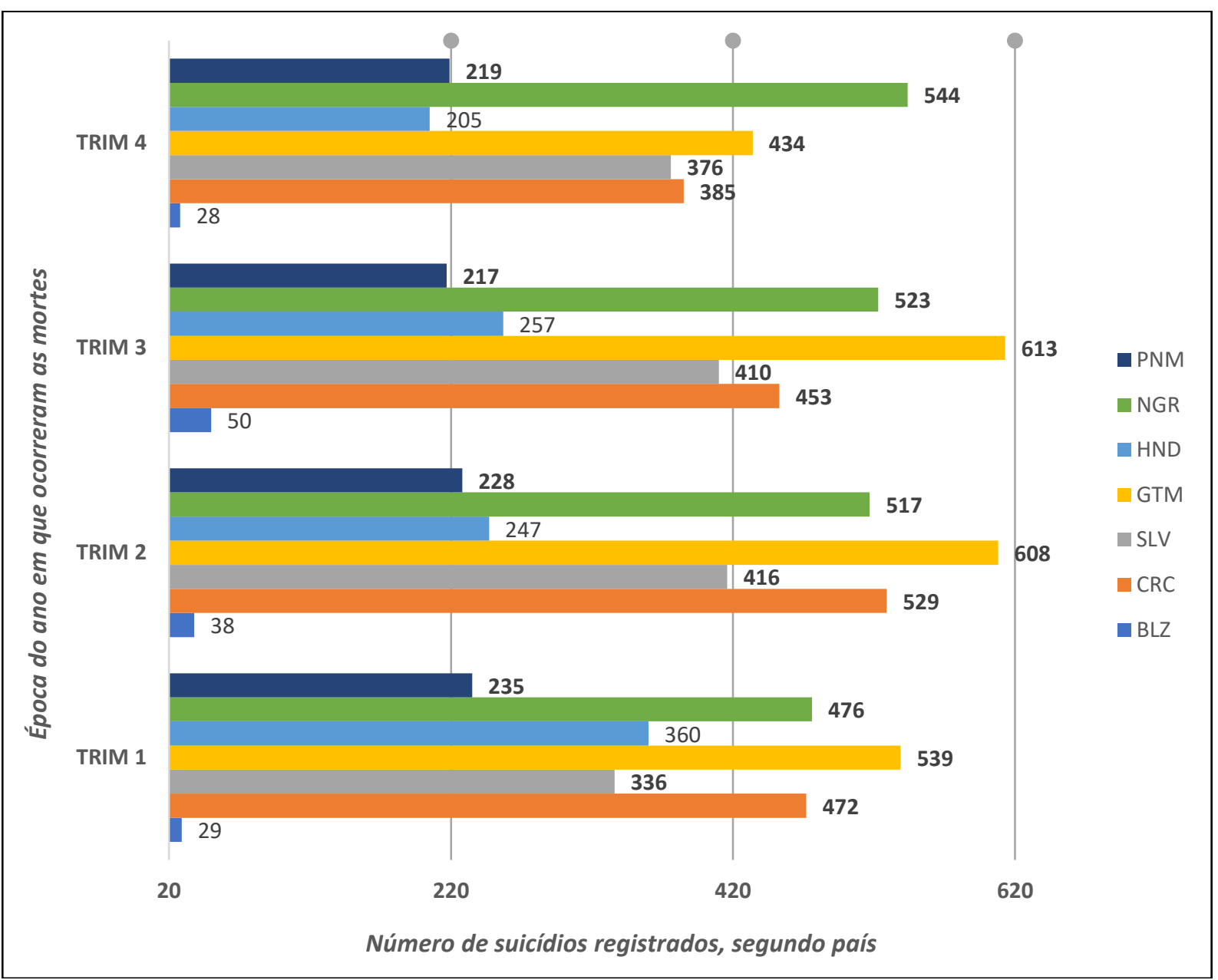

Figura 02 - Comportamento temporal dos suicídios consumados segundo época do ano e país de origem do agente,

América Central Continental, 2010-2016.

Fonte: Elaboração própria dos autores (2020). 
Ao se observar a mortalidade por sexo, percebeu-se que as mulheres decidem finalizar suas vidas com maior incidência durante os meses de abril, maio e junho (segundo trimestre; $\mathrm{n}=643 ; 28,5 \%)$. No caso dos homens, os meses mais recorrentes para consumar o suicídio são: julho, agosto e setembro (terceiro trimestre; $n=1957 ; 26,13 \%$ ). A relação entre a época do ano e a consumação do ato suicida merece ser estudada com maior profundidade e de forma multidimensional, uma vez que o suicídio é um problema de saúde coletiva, predominantemente, masculino.

\section{Discussão}

De acordo com Hein e Larrobla (2017, p. 14), atualmente, falar em suicídio remete, necessariamente, a "colocar sobre a mesa uma das questões que persiste no século XXI, não apenas como tabu, mas há também um enigma e um estigma que nos levam a cobri-lo com um manto que o esconde, silencia e condena". Em seguida, os mesmos autores comentam que esse fato se deve a uma conjunção de dimensões que, individual e isoladamente, são mais fáceis de refutar, mas amalgamados na trama social conjugam um prisma que se torna difícil tanto na sua desconstrução quanto na sua observação.

Complementarmente, Madrid (2019) levanta considerações entrelaçando comunidade, saúde mental, e cidadania em países latino-americanos, debatendo, principalmente, o posicionamento dos Estados e o real alcance das políticas públicas voltadas à atenção das premências da saúde mental coletiva:

A saúde mental na América Latina se desenvolveu nas últimas décadas, de acordo com uma abordagem comunitária. Em vários países da região, esse modelo promoveu avanços na reconversão dos cuidados psiquiátricos em asilo; no entanto, uma avaliação crítica dos processos de reforma sustenta que eles envolveram apenas uma reorganização geográfica dos serviços de saúde, reproduzindo a lógica do hospício no território (MADRID, 2019, p. 01, tradução livre do espanhol).

Na ótica do suicídio como questão de saúde coletiva, podem-se trazer os apontamentos de Urie Bronfenbrenner e seu Modelo Bioecológico que, segundo Zillmer et al. (2011):

[...] possibilita a investigação e a análise do fenômeno por meio de quatro núcleos inter-relacionados: pessoa, processo, contexto e tempo; e também é denominado de modelo PPCT. Ele promove o conhecimento de como essas pessoas ou grupo familiar vivenciam determinada experiência (processo), inseridas em diferentes contextos. Esses contextos possuem aspectos físicos, sociais e valorativos, que os caracterizam e exercem influência na pessoa e no grupo familiar, pela continuidade (tempo) e estabilidade do sistema de relações e da construção de suas rotinas, de sua biografia e história social (ZILLMER et al., 2011, p. 670). 
Haro; Pascual e Gonzáles (2018, p. 384) afirmam que "o suicídio, para mais de um problema de saúde coletiva/pública e saúde mental, é um drama pessoal, familiar e social, no qual fatores culturais, sociais, psicológicos, clínicos e biológicos merecem especial consideração". Segundo os autores:

[...] Ao investigar fatores de risco para suicídio, a literatura fala sobre duas séries de fatores bem documentados: 1) uma lista de problemas da vida cotidiana e 2) uma lista de diagnósticos psiquiátricos: ver depressão, transtorno bipolar, esquizofrenia, transtorno de personalidade, alcoolismo ou abuso de substâncias. A citação "psi" é famosa, segundo a qual $90 \%$ das pessoas que se suicidam tiveram ou sofreram de um distúrbio mental subjacente. [...] Embora na problemática do suicídio você possa encontrar problemas da primeira série sem diagnóstico da segunda, é raro encontrar diagnósticos da segunda sem problemas da primeira (HARO; PASCUAL; GONZÁLES, 2018, p. 388, tradução livre do espanhol).

Ponto fundamental em relação à abordagem multidimensional do suicídio é entender que tal fenômeno/comportamento epidemiológico está, indubitavelmente, associado ao contexto social em que as pessoas estão inseridas; convertendo-o, desse modo, em um desafio de alta complexidade para as sociedades atuais. Rocha, Boris e Moreira (2012, p. 01) caracterizam o suicídio como uma "vivência de aniquilamento existencial", ressaltando que as condições culturais e socioeconômicas em torno do suicídio devem ser sistematicamente consideradas e aprofundadas para uma melhor compreensão desse fenômeno social.

O local de residência configura um dos espaços mais recorrentes pelos agentes para a consumação do ato suicida. Logo, percebe-se a família como elemento essencial para a prevenção/livramento/combate social do suicídio. A somar:

Sexo, faixa-etária, cultura e etnia têm implicações importantes na epidemiologia do suicídio. As taxas globais evidenciam vulnerabilidade para dois picos de idade: 15 a 35 anos e de 75 anos ou mais. Ademais, por cada óbito por suicídio cinco ou seis pessoas são afetadas do ponto de vista emocional, social e econômico" (MINAYO, 2017, p. 18).

Para Rocha, Boris e Moreira (2012) fica claro que:

[...] as tentativas de suicídio são mal compreendidas pelas pessoas, muito em função dos inúmeros fatores associados a esta experiência. [...] familiares e amigos acabam por fazer uma análise superficial da situação em que se encontra o suicida e concluem que a tentativa aconteceu por alguma condição anterior, vivida pelo indivíduo, como uma possessão demoníaca ou a perda da razão, por exemplo (ROCHA; BORIS; MOREIRA, 2012, p. 77).

Um dos maiores desafios no manejo do suicídio como problema de saúde coletiva/pública é o inegável tabu que as sociedades lhe atribuem, dificultando o trabalho dos 
profissionais da saúde e, portanto, a resolutividade do próprio sistema de assistência social e sanitária. Acentuando essa questão, Cavalieri (2009, p. 180) diz que: 1) "o suicida, segundo a crença religiosa, comete um pecado mortal ao atentar contra a vida". Nem sempre foi considerado algo pecaminoso ou crime e, 2) “em nossa cultura não se fala tanto da morte ou da velhice, pois representam a finitude do ser. Parece que o homem não consegue encarar frente-a-frente a situação de limite". O trabalho de Silva; Barbosa (2019), por outro lado, afirma que a religião pode ser considerada como um fator de proteção em indivíduos que tentaram suicídio e não o consumaram, relacionando a crença com a possibilidade de renovação do indivíduo, aumentando sua capacidade de resiliência e, desse modo, diminuindo as chances da fatalidade suicida.

Walsh e McGoldrick (2004), ao estudarem a morte dentro do sistema familiar e os fenômenos que implicam na sobrevivência dos demais membros às perdas, comentam que:

\footnotetext{
Quando ocorre um suicídio, a raiva e a culpa podem tomar conta das relações familiares, particularmente quando os membros são culpados ou culpam-se a si mesmos pela morte. $\mathrm{O}$ estigma social do suicídio também contribui para a vergonha e o encobrimento das circunstâncias por parte da família. Estes segredos, destorcem a comunicação familiar e podem isolar a família do apoio social, gerando seu próprio legado destrutivo (WALSH; MCGOLDRICK, 2004, p. 42).
}

Outrossim, Rodrigues (2009, p. 153) aporta que "é fundamental, portanto, encontrar formas plurais de problematizar e pensar o suicídio". Para a autora, é preciso discutir, debater, estudar, analisar e interrogar o ato para, em seguida, compreender o que leva uma pessoa ao suicídio, a não mais querer a vida, pelo menos uma condição específica de vida. Isso porque, atualmente, "a saúde tem se tornado uma exigência mais do que um direito social, ela é objeto de consumo e fonte de valor social” (BETANCORT; RODRÍGUES; PÉREZ, 2019, p. 205).

Por outro ângulo, García; Contreras e Rodrígues (2006) relacionam o suicídio a outros transtornos de índole mental, a saber: depressão grave, transtorno de bipolaridade, esquizofrenia, etilismo, consumo abusivo de substâncias fármaco-químicas, ansiedade, anorexia, e transtornos da personalidade. Acrescentando a tais influências, as autoras defendem que a complexidade do manejo do suicídio e das estratégias de avaliação, detecção de risco e prevenção se encontram atalhadas pelo desconhecimento duma definição e classificação operativa. Reyes (2002), por outro lado, sustenta que ao se realizarem análises epidemiológicas sobre o suicídio, é necessário partir duma concepção ampla e profunda sobre a saúde coletiva/pública, na busca da maior utilidade dessas análises, podendo ser aproveitadas em ações que considerem as características do modelo de atenção sociossanitária e a significação social do processo saúde - doença - cuidados. A visão de Reyes (2002) 
evidencia que de nada valeria realizar intervenções diretas com indivíduos que apresentam potencial/histórico suicida, se o próprio sistema de assistência social e sanitária não possui a capacidade resolutiva para tratar a complexidade multidimensional que envolve o fenômeno.

Desse modo, se corrobora a urgente necessidade de construir uma identidade assistencial norteada sob o reconhecimento das potencialidades e, também, das fraquezas do sistema social, em relação às doenças/transtornos mentais. Mormente, faz-se jus falar em longitudinalidade da atenção oferecida, ou seja, não se trata simplesmente do cuidado imediato (que pode ser traduzido, no melhor dos cenários, na prevenção do ato suicida); mas também do acompanhamento paliativo desse transtorno, a fim de dotar o indivíduo com potencial/histórico suicida de ferramentas para procurar assistência profissional, em situações estressantes que possam agravar seu estado de sofrimento mental. Portanto, a perspectiva longitudinal da atenção sociossanitária do suicídio é, sem espaço de hesitação, uma questão biopsicossocial preconizada pela saúde coletiva.

Considerando os múltiplos fatores de risco relacionados ao suicídio, a OPAS (2014) classifica-os em cinco dimensões principais, a saber: 1) sistemas de saúde (barreiras no acesso à atenção em saúde); 2) sociedade (acesso aos meios utilizados para consumar o suicídio, subnotificação pelos meios de comunicação, uso de redes sociais); 3) comunidade (guerras, desastres, conflitos); 4) relações (sentimento de isolamento e falta de apoio social, conflitos sentimentais, brigas e/ou perdas), e 5) indivíduo (histórico de tentativa de suicídio, transtornos mentais, consumo nocivo de álcool, desemprego e/ou crise financeira, dor crônica, fatores genéticos e biológicos).

Em relação as condutas suicidas, Suelves e Robert (2012) afirmam:

Elas estão sujeitas a determinantes parcialmente conhecidos e podem ser impedidos de estratégias que incluem tanto a detecção precoce quanto o tratamento de pessoas com maior risco de comportamento suicida e medidas populacionais para controlar o acesso a possíveis meios suicidas, o desenvolvimento de políticas redução do uso de álcool e adoção de práticas responsáveis na denúncia de suicídio pela mídia (SUELVES; ROBERT, 2012, p. 01, tradução livre do espanhol).

Tal estudo corrobora com o padrão americano masculino suicida, indicando-o como um comportamento de menor incidência entre mulheres (REYES, 2002; HERRERA et al., 2009; OPAS, 2014). No hemisfério sul-americano, pesquisas também defendem que o suicídio é expressivamente maior em populações masculinas (MOLINA; LECHUGA, 2003; MUÑOZ et al., 2005; MINAYO, 2017). No hemisfério norte-americano, investigações apontam na mesma direção (HERNÁNDEZ et al., 2004, OPAS, 2014). 
Ao se analisarem as realidades sociossanitárias, segundo país, se notou que a Costa Rica e o Panamá apresentam os melhores índices de desenvolvimento na sub-região. No entanto, a Costa Rica é o segundo país com maior número de suicídios na ACC. Nessa hipótese que relaciona a realidade sociossanitária mais favorável a menos casos de suicídio, a Guatemala merece destaque. Nesse país, o investimento estatal encontra-se abaixo da média sub-regional nos três setores públicos (educação, saúde e sociedade); e é o local da ACC que mais registra mortes suicidas. Tal divergência hipotética entre a Costa Rica e a Guatemala ressalta a complexidade multidimensional do suicídio, bem como seus fatores de risco e de proteção.

Por outro lado, a investigação desenvolvida por Herrera et al. (2009) objetivou analisar as taxas de suicídio na ACC entre 1988 e 2008. Os resultados mais relevantes desses autores mostraram que, nesse período, Panamá, Costa Rica, e Nicarágua foram os países que sofreram maior incremento no índice nacional de suicídios respectivamente. $\mathrm{O}$ estudo ainda ressaltou baixos índices de suicídio em Belize; contudo, relatou dificuldades técnicas para coletar dados sobre o referido território. Os autores concluem seu trabalho reforçando que os dados de origem panamenha, costa-riquenha, e nicaraguense apresentaram melhor qualidade de registro e de coleta.

Mora; Moya e Calderón (2019) analisaram o registro médico-legal (autopsias) de 353 indivíduos costa-riquenhos que decidiram acabar com suas próprias vidas entre 2010 e 2016. Os autores referem que 91,8\% não apresentaram tentativa de autoeliminação; 35,4\% tinham antecedentes patológicos vinculados à depressão; 74,5\% não apresentaram registros de dificuldades/problemas familiares; 36,5\% tinham antecedentes de etilismo e, somente, $24,9 \%$ tinham registros de dependência de substâncias químicas. Em relação à consumação do ato suicida, $62 \%$ das mortes ocorreram por enforcamento; 17,8\% por intoxicação (substâncias químicas), e $15 \%$ por ferida de bala.

$\mathrm{Na}$ Guatemala, uma investigação que analisou o perfil dos suicídios e de suas tentativas registrados pelo Hospital Nacional de Jutiapa, apontou que o suicídio é um comportamento característico em homens agricultores, tendo como principais fatores de risco: transtorno de bipolaridade e histórico de depressão. No tangente à tentativa suicida não consumada, houve maior incidência em homens colegiais e universitários com histórico de conflitos no núcleo familiar e consumo nocivo de produtos fármaco-químicos (SANDOVAL; HERNÁNDEZ; GARCÍA, 2016, p. 61). Desse modo, os dados são congruentes com a bibliografia relacionada (RODRIGUES, 2009; OPAS, 2014; MINAYO, 2017), ao demonstrar 
que o consumo de drogas e/ou de álcool, especificamente, são fatores de risco para a consumação do ato suicida.

Entre os escassos estudos que correlacionam o uso de agrotóxicos e o suicídio, Pires, Caldas e Recenas (2005) assinalam que:

\begin{abstract}
Um estudo conduzido na Espanha mostrou que a taxa de suicídios em áreas agrícolas é significativamente maior que em outras regiões geográficas com características socioeconômicas e demográficas similares. No Canadá foi observado um significativo aumento do risco de suicídios em grupos de agricultores que aplicavam inseticidas e herbicidas comparados com grupos não expostos, e nos Estados Unidos, Van Wijngaarden observou que o maior risco de suicídios pela exposição a agrotóxicos ocorria em indivíduos entre 35 e 49 anos (PIRES; CALDAS; RECENAS, 2005, p. 602).
\end{abstract}

Retomando os resultados desse estudo em relação à mortalidade de acordo com a época do ano em que ocorrem os suicídios, fica claro que os meses de abril, maio, e junho concentram maior frequência de passamentos. Assim, torna-se interessante conhecer quais são os fatores/elementos que influenciam tal fenômeno no segundo trimestre do ano. Essas informações podem servir como norte para a implementação de ações promotoras de resiliência e de prevenção do comportamento suicida. Sabendo-se que nesses meses do ano o número de suicídios é superior, em comparação aos outros, ações estatais devem ser reforçadas nesse período - conscientização social, acompanhamento dos agentes com histórico de tentativa, e aprimoramento profissional dos trabalhadores da saúde. Entretanto, ressalta-se que atividades prioritárias não devem ser desmerecidas ou menos apreciadas nos outros trimestres, uma vez que o que se almeja é um acompanhamento simétrico e uma capacidade de resposta resolutiva ao suicídio como problema de saúde coletiva na ACC.

A maioria dos estudos ecológicos apresentam certas barreiras técnicas, por dependerem de dados secundários (ARAGÃO, 2011). Nesse sentido, uma limitação desse trabalho foi o fato de não ter tido acesso às características sociodemográficas mais específicas dos agentes, por exemplo: idade, raça, religião, escolaridade, entre outras. Isso se deveu a base de dados do Observatório ser alimentada unicamente com valores absolutos das mortes trimestrais. Ademais, é acenar que não foi possível encontrar registros para Guatemala e Nicarágua no ano de 2016, nem para os dois últimos trimestres na Costa Rica, fato que predispõe análises mais precisas desses países.

Tal situação pode ser considerada como uma fragilidade da vigilância epidemiológica na sub-região continental centro-americana. Conquanto, as limitações na compilação e na apresentação dos registros de mortalidade por suicídio são reiteradamente levantadas em 
debates epidemiológicos (REYES, 2002). Ademais, relatórios e informes oficias desenvolvidos pela OMS destacam às limitações dos estudos que se importam em apontar o impacto da realidade sociossanitária no suicídio, indicando que as aproximações estatísticas do suicídio representam mortes mal documentadas e proporções desconhecidas na maioria dos casos (OPAS, 2014). Mesmo com tal limitação, as informações apresentadas nesse estudo se traduzem em grande valor para a saúde coletiva centro-americana, na medida em que vêm a reforçar o debate da prevenção do suicídio e das questões socioculturais que o cercam, por meio da conscientização sob o número de vidas que têm se perdido, em decorrência da atual incapacidade resolutiva dos sistemas de assistência social e sanitária na ACC.

Finalmente, ressalta-se que essa pesquisa não pretendeu esgotar o tema, pois se reconhece a necessidade de realizar múltiplas análises que levem em consideração aspectos subjetivos, sob a perspectiva biopsicossocial da saúde. Nesse pensamento, instila-se a realização de futuras pesquisas a nível nacional e sub-regional, que possam ser de auxílio para a abordagem centro-americana no combate e na prevenção do suicídio. Quiçá, pesquisas que visem realizar comparações entre o meio rural, o meio urbano e o consumo de agrotóxicos, por serem aspectos já destacados na literatura. Há escassa informação de estudos que comparem as taxas de suicídio entre as zonas urbana e rural, a qual Arias e Blanco (2010) afirmam ser uma área de relevância imediata que deve ser abordada pela saúde coletiva dos países latino-americanos, uma vez que a taxa de suicídio na América Latina encontra-se em tendências positivas (crescimento); especialmente, nas zonas rurais - ainda que o registro das mortes em zonas urbanas pareça ser maquiado por números imprecisos.

Para cada registro de óbito suicida pode-se somar mais uma tentativa empobrecida do sistema, falhas dos profissionais incumbidos e estigma social que envolve esse fenômeno multidimensional. A conscientização e a prevenção do suicídio não é uma tarefa exclusiva de alguns, pois compete a todos desmistificarmos os preconceitos sociais na busca por novas abordagens mais dignas e mais eficazes. Afinal, a conscientização sobre o suicídio como problema de saúde coletiva nada mais é do que uma questão de humanização dos cuidados em saúde.

\section{Considerações Finais}

Indubitavelmente, as constantes mudanças nos perfis sociossanitários da sub-região continental centro-americana, ao longo do período estudado, vêm aumentando as linhas de tensão dos transtornos mentais. Isso se deve tanto pela pronunciada incapacidade dos sistemas de saúde e de assistência social de responder às exigências dos usuários (fundamentada nos 
cenários da má organização e da desestruturação do cuidado ofertado); quanto pela subestimação dos próprios usuários sobre doenças e agravos mentais, haja vista o preconceito que cerca o suicídio.

Nesse contexto, o suicídio se (re)afirma com um dos principais problemas de saúde coletiva na presente década. A sua abrangência, para além do território centro-americano, demanda debate mundial, requisitando intervenções imediatas que visem sua identificação precoce, tratamento/acompanhamento, e prevenção; bem como reforço das práticas intersetoriais (setores sanitário e social), do estabelecimento de mecanismos articulados, e de uma linha de atuação que privilegie o trabalho interprofissional (centrado, prioritariamente, nos indivíduos).

O custo do suicídio para os sistemas de saúde pública e de assistência social deve ser compreendido para além da própria demanda dos serviços. $\mathrm{O}$ agente que comete suicídio não representa posterior gasto para os sistemas (no sentido de que não requer acompanhamento). Precisa-se considerar que, por trás desse óbito, existem outros indivíduos com vínculos familiares, sentimentais e/ou sociais. Esses devem ter acompanhamento biopsicossocial na maior capacidade do sistema sociossanitário a título de prevenção de âmbito transgeracional.

No panorama continental centro-americano observado, foi possível evidenciar perfis de mortalidade bastante divergentes entre si, retratando realidades nacionais que merecem ser estudadas de maneira mais aprofundada e com metodologias multidisciplinares, que não se preocupem simplesmente em empregar técnicas quantitativas - fazendo-se mister qualificar os contextos desses óbitos. Assim, o Modelo Bioecológico configura-se como preeminente opção para a abordagem desse agravo mental.

Por último, o principal aporte desse trabalho foi sua característica de inovação, mesmo que parcial, para preencher a lacuna científica que envolve o estudo do fenômeno epidemiológico do suicídio na sub-região continental centro-americana. Tais estudos ainda são escassos, impossibilitando análises comparativas mais efetivas entre os referidos países.

\section{Referências}

ARAGÃO, J. Introdução aos estudos quantitativos utilizados em pesquisas científicas. Práxis, [S.1.], v. 3, n. 6, p. 59-62, 2011. Disponível em: http://revistas.unifoa.edu.br/index.php/praxis/article/view/566/0. Acesso em: 12 dez. 2019.

ARIAS, E; BLANCO, I. Una aproximación al entendimiento del suicidio en zonas rurales y remotas de América Latina. Estudios Sociológicos, [S.1.], v. XXVIII, n. 82, p. 185-210, 2010. 
Disponível em: https://www.redalyc.org/pdf/598/59820675008.pdf. Acesso em: 01 jan. de 2020.

BETANCORT, E. M. N.; RODRÍGUEZ, J. H.; PÉREZ, P. L. Los límites de la prevención del suicidio. Revista Asociación Española de Neuropsiquiatría, [S.1.], v. 39, n. 135, p. 193-214, 2019. Disponível em: http://www.revistaaen.es/index.php/aen/article/view/17085. Acesso em: 10 jan. 2020.

MINISTÉRIO DA SAÚDE DO BRASIL - MS. Resolução nº 446, de 12 de dezembro de 2012. Disponível em:

https://bvsms.saude.gov.br/bvs/saudelegis/cns/2013/res0466_12_12_2012.html Acesso em: 19 jan. 2020.

CAVALIERI, E. O suicídio na abordagem fenomenológica. In: CAMPOS, I. F. (Org.). Vidas interrompidas. Vitória: DIO, 2009. Disponível em:

https://ciatox.es.gov.br/Media/toxcen/Material\%20Informativo/6-

Livro\%20Vidas\%20Interrompidas\%20-

\%20Preven\%C3\%A7\%C3\%A3o\%20do\%20Suic\%C3\%ADdio.pdf. Acesso em: 22 dez. 2019.

CONSEJO DE MINISTROS DE SALUD DE CENTROAMÉRICA - COMISCA.

Observatorio Centroamericano y República Dominicana de la conducta suicida, 2018.

Disponível em: http://comisca.net/content/observatorio_suicidio?Idm=1. Acesso em: $12 \mathrm{dez}$. 2019.

COMISIÓN ECONÓMICA PARA AMÉRICA LATINA Y EL CARIBE. Base de datos y publicaciones estadísticas. Perfiles nacionales. Disponível em:

https://estadisticas.cepal.org/cepalstat/perfilesNacionales.html?idioma=spanish Acesso em: 12 dez. 2019.

FERNÁNDEZ, L. G. et al. Suicidio en el adulto mayor. Revista Información Científica, [S.1.], v. 76, n. 4, 2012. Disponível em:

http://www.revinfcientifica.sld.cu/index.php/ric/article/view/819/1777. Acesso em: 23 jan. 2020.

GARCÍA, A. G. G.; CONTRERAS, C. M.; RODRÍGUEZ, R. C. O. El suicidio, conceptos actuales. Salud Mental, [S.1.], v. 29, n. 5, p. 66-74, 2006. Disponível em:

https://www.redalyc.org/pdf/582/58229510.pdf. Acesso em: 15 dez. 2019.

GUEDES, T.A et al. Estatística descritiva. Projeto de ensino aprender fazendo estatística. 2005. Disponível em:

http://www.each.usp.br/rvicente/Guedes_etal_Estatistica_Descritiva.pdf. Acesso em: 30 abr. 2020.

HARO, J. G.; PASCUAL, G. H.; GONZÁLEZ, M. G. Un enfoque contextualfenomenológico sobre el suicidio. Revista Asociación Española de Neuropsiquiatría, [S.1.], v. 38, n. 134, p. 381-400, 2018. Disponível em:

http://www.revistaaen.es/index.php/aen/article/view/17052. Acesso em: 02 dez. 2019. 
HEIN, P.; LARROBLA, C. Introdução geral. In: CANETTI, A. et al. (Orgs.). 70 años de Suicidio en Uruguay: 7 disciplinas, 7 entrevistas, 7 encuentros. Montevideo, Uruguay: González, Víctor, 2017.

HERNÁNDEZ, A. M. C. et al. Epidemiología del suicidio en el Estado de Guanajuato. Salud Mental, [S.1.], v. 27, n. 2, p. 15-20, 2004. Disponível em:

http://www.revistasaludmental.mx/index.php/salud_mental/article/view/991. Acesso em: 29 dez. 2019.

HERRERA, A.; SOLORZANO, L.; BASAURI, V. A.; CALDERA, T. Suicidio en Centroamérica y República Dominicana, 1998-2008. Cuadernos de Psiquiatría Comunitaria, [S.1.], v. 9, n. 2, p. 177-186, 2009. Disponível em: http://www.aen.es/docs/Cuadernos9.2.pdf. Acesso em: 12 jan. 2020.

LIMA-COSTA, M. F.; BARRETO, S. M. Tipos de estudos epidemiológicos: conceitos básicos e aplicações na área do envelhecimento. Epidemiologia e Serviços de Saúde; 12(4): 189 - 20, 2003. Disponível em: http://dx.doi.org/10.5123/S1679-49742003000400003. Acesso em: 07 jan. 2020.

MADRID, J. C. C. Locos por nuestros derechos: comunidad, salud mental y ciudadanía en el Chile contemporáneo. Quadernos de Psicologia, [S.1.], v. 21, n. 2, e1502, 2019. Disponível em: https://www.quadernsdepsicologia.cat/article/view/v21-n2-Cea. Acesso em: $12 \mathrm{dez}$. 2019.

MINAYO, M. C. S. Suicídios nas Américas: um problema de saúde pública e para a sociedade. In: CANETTI, A. et al. (Orgs.). 70 años de Suicidio en Uruguay: 7 disciplinas, 7 entrevistas, 7 encuentros. Montevideo, Uruguay: González, Víctor, 2017.

MOLINA, R.T; LECHUGA, E.N. Factores de riesgo asociados al suicidio e intento de suicidio. Salud Uninorte, [S.1.], n. 17, p. 19-28, 2003. Disponível em: https://www.redalyc.org/pdf/817/81701703.pdf. Acesso em: 07 jan. 2020.

MORA, M. T.; MOYA, D. Z.; CALDERÓN, J. E. Análisis de lesionología de una muestra de 353 autopsias de suicidios, Departamento de Medicina Legal, Costa Rica del 2010 al 2016. Revista Medicina Legal de Costa Rica, [S.1.], v. 36, n. 2, p. 06-16, 2019. Disponível em: https://www.scielo.sa.cr/pdf/mlcr/v36n2/2215-5287-mlcr-36-02-6.pdf. Acesso em: 07 jan. 2020.

MUÑOZ, J. V.; VEGA, D. J.; MENDOZA, A.; MUÑOZ, V. H. Suicidio e intento de suicidio por salto desde altura en el Puente Villena. Revista de Neuro-Psiquiatría, [S.1.], v. 68, n. 3-4, p. 140-152, 2005. Disponível em:

http://sisbib.unmsm.edu.pe/BVRevistas/Neuro_psiquiatria/v68_n3-4/pdf/a03.pdf. Acesso em: 07 jan. 2020.

ORGANIZAÇÃO PAN-AMERICANA DA SAÚDE. Folha informativa: suicídio, 2018. Disponível em: 
https://www.paho.org/bra/index.php?option=com_content\&view=article\&id=5671:folhainformativa-suicidio\&Itemid=839 Acesso em: 29 jan. 2020.

ORGANIZACIÓN MUNDIAL DE LA SALUD. Clasificación internacional de enfermedades - CIE-11, 2019. Disponível em: https://icd.who.int/browse11/1m/es\#/http\%3a\%2f\%2fid.who.int\%2ficd\%2fentity\%2f851395624 Acesso em: 14 jan. 2020.

ORGANIZACIÓN PANAMERICANA DE LA SALUD. Informe regional: mortalidad por suicidio en las Américas. Washington D. C., 2014. Disponível em: https://www.paho.org/hq/dmdocuments/2014/PAHO-Mortalidad-por-suicidio-final.pdf Acesso em: 07 jan. 2020.

PIRES, D. X.; CALDAS, E. D.; RECENA, M. C. P. Uso de agrotóxicos e suicídios no Estado do Mato Grosso do Sul, Brasil. Cadernos de Saúde Pública, [S.1.], v. 21, p. 598-604, 2005. Disponível em: https://www.scielo.br/pdf/csp/v21n2/27.pdf. Acesso em: 09 dez. 2019.

REYES, W. G. Epidemiología de la conducta suicida. Revista Cubana de Medicina General Integral, Ciudad de La Habana, v. 18 n. 2, 2002. Disponível em:

http://scielo.sld.cu/scielo.php?script=sci_arttext\&pid=S0864-21252002000200007. Acesso em: 11 jan. 2020.

ROCHA, M. A. S.; BORIS, G. D. J.; MOREIRA, V. A experiência suicida numa perspectiva humanista-fenomenológica. Revista da Abordagem Gestáltica, [S.1.], v. XVIII, n. 1, p. 69-78, 2012. Disponível em: http://pepsic.bvsalud.org/scielo.php?script=sci_arttext\&pid=S180968672012000100010. Acesso em: 22 dez. 2019.

RODRIGUES, M. B. F. Suicídio, tabu e silêncio. In: CAMPOS, Í. F. (Org.). Vidas interrompidas. Vitória: DIO, 2009.

SANDOVAL, M. T. R.; HERNÁNDEZ, J. L. A.; GARCÍA, O. W. C. C. Informe final: conducta suicida y factores asociados en la ciudad de Jutiapa. Guatemala: Universidad Juan Carlos de Guatemala, 2016. Disponível em: https://digi.usac.edu.gt/bvirtual/informes/puiis/INF-2016-30.pdf. Acesso em: 02 jan. 2020.

SCHNEIDER, A. População e perfil sanitário: perspectivas para 2030. Fundação Oswaldo Cruz: Saúde amanhã. Publicado em setembro de 2014. Disponível em: https://saudeamanha.fiocruz.br/populacao-e-perfil-sanitario-perspectivas-para2030/\#.XhudalMzbpA. Acesso em: 28 jan. 2019.

SILVA, J. A.; BARBOSA, C. A. N. O suicídio na visão da doutrina espírita e das ciências: revisão de literatura. Revista Psicologia Saúde e Debate, [S.l.], v. 5, n. 2, p. 96-111, 2019. Disponível em:

http://psicodebate.dpgpsifpm.com.br/index.php/periodico/article/view/V5N2A7. Acesso em: 13 de janeiro de 2020.

SISTEMA DE INTEGRACIÓN CENTROAMERICANA - SICA. Consejo de ministros de salud de Centroamérica (COMISCA). Quiénes somos: COMISCA y su secretaria ejecutiva, 2013. Disponível em: https://www.sica.int/comisca/breve.aspx. Acesso em: 22 jan. 2020. 
SUELVES, J. M.; ROBERT, A. La conducta suicida: una mirada desde la salud pública. Revista Española de Medicina Legal, [S.1.], v. 38, n. 4, p. 137-142, 2012. Disponível em: https://www.elsevier.es/es-revista-revista-espanola-medicina-legal-285-articulo-la-conductasuicida-una-mirada-S0377473212000879. Acesso em: 10 dez. 2019.

VENCO, S.; BARRETO, M. O sentido social do suicídio no trabalho. Revista do Tribunal Superior do Trabalho, Brasília, vol. 80, no 1, 2014. Disponível em:

https://juslaboris.tst.jus.br/handle/20.500.12178/61186. Acesso em: 19 de dezembro de 2019.

WALSH, F; MCGOLDRICK, M. Morte na família: sobrevivendo às perdas. Artmed, 2004.

ZILLMER, J. G. V. et al. Modelo bioecológico de Urie Bronfenbrenner e inserção ecológica: uma metodologia para investigar famílias rurais. Texto contexto -

enfermagem, Florianópolis, v. 20, n. 4, p. 669-674, dez. 2011. Disponível em:

https://www.scielo.br/scielo.php?pid=S0104-

07072011000400004\&script=sci_abstract\&tlng=pt. Acesso em: 09 jan. 2020. 